\section{For quiet students, finding a voice is the first step towards taking a stand}

\section{SIR - As a Chinese graduate student} studying in Canada, I often hear stories that reflect your News Feature "Taking a stand $^{\text {" }}$ (Nature 438, 278-279; 2005), about my Asian colleagues feeling mistreated by their lab-mates.

The Ontario Human Rights Code states that "individuals have the right to equal opportunities in the workplace and to an educational environment free of harassment because of colour, age, sex, sexual orientation, ethnic origin, religion and handicap". The United States has a similar law. I would like to think that mistreatment of the Chinese workforce in North American graduate schools is minimal at most, yet I fear that this is not a realistic hope.

Although I currently work in a friendly and cooperative lab and feel fortunate to have helpful and supportive co-workers, $\mathrm{my}$ comfort does not mean that discrimination does not exist elsewhere.

A number of my Chinese friends in North America, including one senior postdoc, have, in my opinion, been discriminated against. Unfortunately, a traditional Chinese upbringing encourages passive and nonverbal avoidance of conflict. Furthermore, competition in lab research is fierce, particularly in the United States, so anyone with an obvious weakness such as a language barrier or cultural difference is more likely to be taken advantage of.

To fight for equality in the workplace, one needs to be socially adaptable, and must voice concern if equal rights are being violated.

Peter Cheung

University of Western Ontario,

London Regional Cancer Program,

Room A4-805, 790 Commissioners Road East, London, Ontario N6A 4L6, Canada

\section{Animal culture is real but needs to be clearly defined}

SIR - William Abler, in Correspondence ( ${ }^{\star}$ Evidence of group learning does not add up to culture" Nature 438, 422; 2005), takes issue with Jacqueline Zupp's assertion, also in Correspondence ( $"$ Concern at animal research should not be dismissed ${ }^{\text {"N }}$ Nature 437,1089 ; 2005), that " we now have evidence for animal cultures".

Two points relevant to Abler's concern deserve emphasis in relation to the nowextensive literature on animal traditions, in which terms such as 'culture,' 'cultural transmission' and 'cultural evolution' are routinely applied not to only to primates but also to taxa as diverse as birds and fish references to the 'cultural transmission of birdsong', for example, have been familiar for decades.

First, many biologists treat 'culture' as a synonym for 'tradition', a term defined as objectively as any in the physical sciences. This is no more "emotional vocabulary", to use Abler's description, than other everyday terms such as intelligence, 'memory' and 'innovation.' These terms can also refer to distinctive phenomena in humans, but once objectively defined they are commonly and usefully applied in the science of animal behaviour.

Second, as I explained at greater length in my recent Progress article ${ }^{\alpha}$ The second inheritance system of chimpanzees and humans" (Nature 437, 52-55; 2005), some behavioural scientists do argue that the term and concept of 'culture' should be reserved for traditions that share certain sophisticated features with the human case, such as transmission by teaching.

Either perspective can be effectively employed in comparative and evolutionary analyses, but whichever approach is used, the needs of good science remain the same: when we use everyday words such as 'culture', they must be clearly defined.

\section{Andrew Whiten}

Centre for Social Learning and Cognitive Evolution and Scottish Primate Research Group,

School of Psychology,

University of St Andrews, South Street,

St Andrews KY169JP, Scotland

\section{Women's efforts are more than a drop in the ocean}

SIR - As an oceanographer I enjoyed your recent Insight on Bio-oceanography (Nature $437,335-368 ; 2005)$. But the only female author in this section was the senior editor who wrote the introduction. This is quite surprising, considering the number of highly qualified women in biological oceanography. In fact, $42 \%$ of the members of the American Society of Limnology and Oceanography who are registered as biological oceanographers are women.

I have found that, during the years 2004-2005 (volumes 421-437), Nature published 11 Insights with 68 individual overviews, reviews and/or commentaries. Only 10 of the 134 authors were women, and a woman was the first author in only about $4 \%$ of cases.

In all cases when the author's name caused the slightest doubt about their sex, I searched the web for confirmation. In nearly every case there was a picture available - and although I cannot rule out cross-dressing, I have no reason to suspect it is widespread. In the only case in which I could not find the information I was seeking, I used a name finder to tell me the author's sex.

A balanced sex ratio is impossible to maintain in peer-reviewed publications, and indeed should not be a goal in peer-reviewed articles. But Insights are written by invitation only, so the editors can decide who they believe could best contribute. The editors should make more effort to promote equality in the process of publication.

DanielConley

Department of Marine Ecology, National Environmental Research Institite, DK-4000 Roskilde, Denmark, and Department of Marine Ecology, Aarhus University, DK-8200 Aarhus, Denmark

\section{Network aims to make maths count in Africa}

SIR - Your Editorial "Networks for Africa" (Nature 438, 395; 2005) raises the question of how research and teaching in the mathematical and physical sciences in Africa can best be strengthened. A vital ingredient is surely that, with whatever assistance richer nations can provide, the broader scientific community across Africa should itself plan and manage its own scientific development.

It is in this spirit that the African Academy of Sciences and the International Mathematical Union support a distributed network of African mathematicians in the African Mathematics Millennium Science Initiative, or AMMSI (www.ammsi-maths. org). AMMSI supports research and postgraduate training in mathematics at universities in sub-Saharan Africa. Individual grants are awarded to students and faculty members whose low salaries, high teaching loads and geographic isolation have inhibited their full functioning as teachers, mentors and researchers.

Since 2004, AMMSI and the African Institute for Mathematical Sciences in Cape Town have been working to ensure that the African mathematical community is a fully vested partner in the proposed IT infrastructure network mentioned in your Editorial: the African Mathematical Institutes Net, or AMI-Net.

John Ball

International MathematicalUnion,

Mathematical Institute, 24-29 St Giles', Oxfard OX13LB, UK

Contributions to Correspondence may be submitted to corres@nature.com. They should be no longer than $\mathbf{5 0 0}$ words, andideally shorter. Correspondence letters must be signed by no more than three authors; preferably by one. Published contributions are edited. 